\title{
Hubungan Gaya dan Motivasi Belajar Matematika dengan Prestasi Belajar Matematika Siswa Kelas V SDN Se-Kecamatan Klirong Tahun Ajaran 2017/2018
}

\author{
Chuswatun Chasanah. ${ }^{1}$, Joharman. ${ }^{2}$, M. Chamdani. ${ }^{3}$ \\ 1,2,3 Universitas Sebelas Maret \\ chuswatunchasanah50@gmail.com
}

\section{Article History}

accepted 01/02/2019

approved 01/03/2019

published 01/04/2019

\begin{abstract}
The objectives of this research are to know whether: (1) there is a positive correlation between learning style with learning achievement of Mathematics, (2) there is a positive correlation between learning motivation with learning achievement of Mathematics, and (3) there is a positive correlation between the style and motivation of learning Mathematicswith the achievement of Mathematics learning of the fifth grade students in elementary schools in Klirong sub-district in the academic year of 2017/2018. This research is quantitative research with correlational method. In analyzing the data, the researcher used the 18 version of SPSS application to analize correlational data. The results showed that the correlation between the style and motivation of learning with the achievement of learning mathematics is 0.501 and the result is $25.1 \%$. Based on the analysis and discussion of research results, it can be concluded that there is a relationship between the style and motivation of learning Mathematics with the achievement of learning Mathematics of the fifth grade elementary school students in Klirong sub-district.
\end{abstract}

Keywords: learning style, motivation, Mathematics

\begin{abstract}
Abstrak
Penelitian ini bertujuan untuk membuktikan ada tidaknya (1) korelasi positif gaya belajar dengan prestasi belajar matematika; (2) korelasi positif motivasi belajar matematika dengan prestasi belajar matematika; (3) korelasi positif gaya belajar dan motivasi belajar matematika dengan prestasi belajar matematika siswa kelas V SDN se-Kecamatan Klirong tahun ajaran 2017/2018. Penelitian ini merupakan penelitian kuantitatif dengan metode korelasional. Pengambilan sampel dilakukan dengan teknik cluster random sampling. Pada analisis data penelitian, peneliti menggunakan aplikasi SPSS versi 18 dalam menganalisis korelasi data. Hasil penelitian menunjukkan bahwa nilai korelasi antara gaya dan motivasi belajar dengan prestasi belajar matematika sebesar 0,501 dan besar sumbangannya yaitu 25,1\%. Berdasarkan analisis dan pembahasan hasil penelitian dapat disimpulkan bahwa terdapat hubungan antara gaya dan motivasi belajar matematika dengan prestasi belajar matematika siswa kelas V SDN seKecamatan Klirong.
\end{abstract}

Kata Kunci: gaya belajar, motivasi, matematika 


\section{PENDAHULUAN}

Kemajuan bangsa berkaitan erat dengan SDM (Sumber Daya Manusia) bangsa itu sendiri. Hal tersebut sama seperti yang dijelaskan oleh Mukhid (2007: 120) dalam penelitiannya tentang kualitas pendidikan bahwa bangsa yang berkualitas akan berkorelasi positif dengan peningkatan SDM. Suatu bangsa dapat maju dan berkembang jika SDM bangsa itu berkualitas. Pembentukan SDM yang berkualitas dapat dilakukan melalui jalur pendidikan.

Kualitas pendidikan formal erat kaitanya dengan prestasi belajar siswa. Prestasi belajar yang baik akan menunjukkan bahwa pendidikan dalam sekolah tersebut berkualitas dan begitu pula sebaliknya. Banyak faktor yang mempengaruhi prestasi belajar diantaranya yaitu gaya belajar dan motivasi belajar. Gaya belajar merupakan suatu pendekatan yang dilakukan oleh individu dalam belajar agar lebih mudah untuk mengolah informasi yang diterima. Gaya belajar setiap siswa berbeda-beda. Hal itu karena setiap siswa memiliki cara efektifnya sendiri untuk mengolah informasi yang didapatkan selama kegiatan belajar (Ghufron dan Risnawita, 2014: 42). Penggunaan gaya belajar yang tepat oleh siswa akan membuat prestasi belajarnya meningkat.

Gaya belajar siswa berdasarkan preferensi sensori terbagi menjadi tiga yaitu gaya belajar visual, gaya belajar auditory, dan gaya belajar kinestetic (Gunawan, 2006: 147). Berdasarkan wawancara dan pengamatan yang peneliti lakukan di salah satu SDN di Kecamatan Klirong pada 25 November 2017, siswa kelas V di SDN tersebut sebagian besar memiliki gaya belajar auditory dan gaya belajar visual. Akan tetapi, tidak setiap siswa menyadari gaya belajar efektif yang ia miliki. Kurangnya kesadaran akan gaya belajar yang tepat bagi dirinya, menjadikan siswa tersebut kurang mendapatkan prestasi yang memuaskan. Gunawan (2006: 139) menyatakan siswa yang belajar menggunakan cara atau gayanya sendiri akan mendapatkan hasil belajar yang lebih tinggi atau lebih baik dibandingkan dengan siswa yang belajar dengan sekedarnya tanpa mempergunakan gaya yang dia miliki.

Disamping faktor gaya belajar, terdapat juga faktor lain yaitu motivasi belajar siswa. Menurut Uno (2016: 9), motivasi merupakan suatu dorongan yang timbul oleh adanya rangsangan dari dalam maupun dari luar sehingga seseorang berkeinginan untuk mengadakan perubahan tingkah laku/aktivitas tertentu lebih baik dari keadaan sebelumnya. Berdasarkan pernyataan tersebut dapat diketahui bahwa motivasi antara siswa yang satu dengan lainnya tidak sama. Motivasi bergantung pada rangsangan yang ada disekitar individu. Oleh karena itu, guru wajib memberikan motivasi kepada siswa saat kegiatan belajar. Ada beberapa cara yang dapat dilakukan untuk memberikan motivasi kepada siswa, diantaranya yaitu: (1) memberi angka; (2) pujian; (3) hadiah; (4) kerja kelompok; (5) persaingan; (6) tujuan dan level of aspiration; (7) sarkasme (mengajak siswa yang memiliki hasil belajar yang kurang); (8) penilaian; (9) karyawisata; (10) film pendidikan; dan (11) belajar melalui radio (Hamalik, 2015: 166168).

Kedau faktor tersebut sangat penting dalam kegiatan pembelajaran di sekolah dasar khususnya saat kegiatan pembelajaran matematika. Matematika merupakan salah satu mata pelajaran yang sangat penting untuk dipelajari. Hal tersebut karena ilmu matematika atau kecerdasan logis matematis erat kaitannya dengan berhitung atau penggunaan angka dalam kehidupan sehari-hari (Uno dan Kuadrat, 2009: 100). Selain itu, perlunya motivasi belajar pada mata pelajaran matematika karena matematika merupakan ilmu yang bersifat abstrak, aksiomatik, dan deduktif (Soedjadi dalam Uno dan Kuadrat, 2009: 108). Pernyataan senada juga tertulis pada koran Suara Merdeka (2017: 24) bahwa matematika penting, tetapi tidak disukai oleh siswa. Hal tersebut diungkapkan oleh Edi Winarko Pakar Matematika dari Departemen IImu Komputer dan Elektronika Fakultas MIPA UGM dalam seminar di kampus UNY pada 13 November 2017. Menurut beliau, isi matematika yang abstrak membuat siswa tidak menyukai pelajaran matematika. 
Segala sesuatu yang abstrak membuat siswa sulit untuk mencerna materi, sehingga siswa kehilangan semangat untuk mempelajarinya. Oleh karena itu, gaya belajar dan motivasi belajar matematika sangat diperlukan agar siswa nyaman saat belajar, sehingga prestasi belajar siswa akan baik. Baiknya prestasi belajar siswa memperlihatkan bahwa kualitas belajar siswa juga baik.

\section{METODE}

Desain penelitian yang digunakan yaitu penelitian kuantitatif dengan metode corelational. Penelitian korelasi yaitu sebuah penelitian dimana pada pelaksanaannya melibatkan tindakan pengumpulan data untuk menentukan hubungan serta tingkat hubungan antara dua variabel atau lebih (Sukardi, 2015: 166). Populasi penelitian ini yaitu siswa kelas V SDN se-Kecamatan Klirong sejumlah 834 siswa dengan sampel sebanyak 273 siswa. Teknik sampling yang digunakan clusster random sampling.

Ada beberapa teknik pengumpulan data yang dapat dilakukan dalam kegiatan penelitian, seperti: angket, wawancara, pengamatan, ujian (tes), dokumentasi, dan lain sebagainya Riduwan (2010: 69). Teknik pengumpulan data menggunakan pada penelitian ini yaitu angket dan teknik tes. Instrumen yang digunakan yaitu angket gaya belajar, angket motivasi belajar matematika dan soal tes matematika. Uji prasyarat data penelitian ini yaitu uji normalitas data, uji linieritas data, dan uji multikolinieritas data. Setelah data memenuhi prasyarat yang ditentukan, data akan dianalisis menggunkan analisis regresi berganda variabel dummy, analisis korelasi sederhana, analisis korelasi berganda, dan analisis determinasi $\left(R^{2}\right)$. Analisis determinasi digunakan untuk mengetahui sumbangan variabel $\mathrm{X}$ kepada variabel $\mathrm{Y}$ (Riduwan, 2010: 224).

\section{HASIL DAN PEMBAHASAN}

Penelitian dilakukan dengan memberikan angket gaya belajar, angket motivasi belajar, dan soal tes matematika kepada siswa kelas $V$ di SD yang menjadi sampel penelitian. Uji prasyarat data pada penelitian ini telah terpenuhi yaitu data berdistribusi normal, data linear, dan tidak terjadi multikolinieritas pada variabel $\mathrm{X}$.

Data prestasi belajar matematika terdistribusi normal ditunjukkan dengan nilai signifikansi 0,063 , sedangkan data motivasi belajar matematika terdistribusi normal ditunjukkan dengan nilai signifikansi 0,53. Nilai signifikansi pada kedua variabel tersebut menunjukkan $>0,05$, sehingga data terdistribusi normal.

Data penelitian linear ditunjukkan dari nilai Sig. Deviation from Linearity sebesar 0,144 untuk variabel motivasi belajar dengan prestasi belajar, sedangkan untuk variabel gaya belajar dengan prestasi belajar nilai Sig. Deviation from Linearity sebesar 0,306 . Nilai Sig. Deviataion from Linearity menunjukkan > nilai Sig. $(0,05)$. Oleh karena itu variabel bersifat linear.

Hasil uji multikolinearitas menunjukkan bahwa nilai tolerance 0,986. Hal itu menunjukkan bahwa nilai tolerance $>0,10$, sehingga dikatakan bahwa tidak terjadi multikolinieritas antar variabel bebas pada penelitian.

Setelah uji prasyarat analisis data telah terpenuhi, selanjutnya dilakukan analisis data uji hipotesis. $\mathrm{HO}_{1}$ pada penelitian ini yaitu tidak terdapat korelasi positif antara gaya belajar dengan prestasi belajar matematika siswa kelass V SDN seKecamatan Klirong tahun ajaran 2017/2018. Berdasarkan analisis yang telah dilakukan, didapatkan nilai Sig. $\mathbf{F}$ change yaitu $\mathbf{0 , 0 0 1}$. Hal itu berarti nilai Sig. $\mathbf{F}$ change $<\boldsymbol{\alpha}(\mathbf{0}, 05)$, sehingga $\mathrm{HO}_{1}$ ditolak. Oleh karena itu dapat ditarik kesimpulan bahwa terdapat korelasi positif antara gaya belajar dengan prestasi belajar matematika. Selain itu, diketahui pula nilai $\mathbf{R}$ sebesar $\mathbf{0 , 2 3 2}$ yang menunjukkan bahwa korelasi antara gaya belajar dengan prestasi belajar matematika masuk dalam kategori rendah dilihat dari tabel pedoman interprestasi koefisien korelasi menurut Sugiyono (2017: 231). Pada hasil analisis tersebut, diketahui nilai $\mathbf{R}$ Square yaitu $\mathbf{0 , 0 5 4}$ yang 
berarti bahwa variabel gaya belajar memberikan sumbangan sebesar $5,4 \%$ pada peningkatan prestasi belajar matematika siswa, sedangkan 94,6\% merupakan sumbangan dari variabel lain. Analisis signifikansi pada hipotesis pertama menunjukkan nilai $\boldsymbol{F}_{\text {hitung }}=7,672$, sedangkan nilai $F_{\text {tabel }}$ ( $d \mathrm{k}$ pembilang $=2$ dan $\mathrm{dk}$ penyebut $=269)$ dengan taraf signifikansi $5 \%$ yaitu 3,029 . Hal itu berarti $\mathbf{F}_{\text {hitung }}(\mathbf{7 , 6 7 2})$ $>F_{\text {tabel }}(\mathbf{3 , 0 2 9})$ yang berarti bahwa koefisien korelasi antara gaya belajar dengan prestasi belajar matematika siswa yang ditemukan adalah signifikan (dapat diberlakukan untuk populasi tempat sampel diambil). Hasil penelitian yang dilakukan ini, sesuai dengan teori yang dikemukakan oleh Gunawan (2006: 139) yang menyatakan bahwa siswa yang belajar menggunakan cara atau gayanya sendiri akan mendapatkan hasil belajar yang lebih tinggi atau lebih baik dibandingkan dengan siswa yang belajar dengan sekedarnya tanpa mempergunakan gaya yang dia miliki. Hal tersebut berarti, penggunaan gaya belajar secara maksimal oleh siswa akan mengantarkannya mendapatkan prestasi yang lebih baik. Hasil penelitian ini juga didukung oleh penelitian yang telah dilakukan sebelumnya. Bire, Geradus, dan Bire (2014: 173) dalam penelitiannya menyimpulkan bahwa gaya belajar visual, gaya belajar auditorial, dan gaya belajar kinestetik secara simultan/ bersama-sama maupun secara terpisah dapat mempengaruhi prestasi belajar siswa pada Jurusan Bangunan SMK Negeri 5 Kupang.

Analisis hipotesis kedua menggunakan uji korelasi sederhana. $\mathrm{HO}_{2}$ pada penelitian ini yaitu tidak terdapat korelasi positif antara motivasi belajar matematika dengan prestasi belajar matematika siswa kelass V SDN se-Kecamatan Klirong tahun ajaran 2017/2018. Berdasarkan uji korelasi yang telah dilakukan, ditunjukkan bahwa nilai Sig. (2-tailed) yaitu 0,000. Oleh karena itu, nilai Sig. (2-tailed) $<\alpha(0,05)$ yang berarti $\mathrm{HO}_{2}$ ditolak. Dilihat dari nilai $\mathbf{r}$ pearson ( $r$ hitung) yaitu 0,475 , sedangkan $r$ tabel $(\mathrm{df}=270)$ pada analisis ini yaitu 0,119 . Oleh karena itu, dapat disimpulkan bahwa nilai $r$ hitung $(0,475)>r$ tabel $(0,119)$ yang berarti $\mathrm{H}_{2}$ ditolak. Berdasarkan kedua putusan tersebut, diketahui bahwa terdapat korelasi positif antara motivasi belajar matematika dengan prestasi belajar matematika. Tingkat korelasi pada hipotesis kedua menunjukkan tingkat korelasi yang sedang. Besar sumbangan yang diberikan variabel motivasi belajar matematika terhadap prestasi belajar matematika yaitu sebesar $22,6 \%$. Berdasarkan uji signifikansi (uji t) yang telah dilakukan, diperoleh nilai $\mathbf{t}_{\text {hitung }}=$ 8,878 , sedangkan $t_{\text {tabel }}(\mathbf{d f}=\mathbf{2 7 1})$ yaitu $\mathbf{1 , 9 6 9}$. Oleh karena itu, $t_{\text {hitung }}(8,878)>t_{\text {tabel }}$ $(1,969)$ yang berarti bahwa koefisien korelasi signifikan (dapat diberlakukan untuk populasi tempat sampel diambil).

Hasil penelitian untuk hipotesis kedua ini sesuai dengan penelitian yang dilakukan oleh Jatmiko (2015:211) yang menyatakan bahwa ada hubungan yang signifikan antara motivasi belajar siswa dengan hasil belajar matematika yag diperoleh siswa. Berdasarkan perhitungan yang telah dilakukan menunjukkan bahwa nilai signifikansi (2-tailed) yang diperoleh sebesar 0,031, sehingga nilai Sig. (2-tailed) $<\alpha$ $(0,05)$ yang berarti Ho ditolak. Berdasarkan penelitian dan perhitungan yang dilakukan di atas, dapat diketahui bahwa terdapat hubungan yang positif antara motivasi belajar matematika dengan prestasi belajar matematika. Oleh karena itu, dapat dikatakan bahwa semakin besar motivasi yang dimiliki oleh siswa, maka akan semakin baik pula prestasi belajar yang akan dicapai oleh siswa. Begitu pun sebaliknya, semakin kecil motivasi yang dimiliki oleh siswa, maka akan semakin rendah pula prestasi belajar yang akan dicapai oleh siswa.

Analisis hipotesis ketiga menggunakan korelasi beganda. $\mathrm{HO}_{3}$ pada penelitian ini yaitu tidak terdapat korelasi positif antara gaya dan motivasi belajar dengan prestasi belajar matematika siswa kelass V SDN se-Kecamatan Klirong tahun ajaran 2017/2018. Berdasarkan analisis yang telah dilakukan, diketahui nilai Sig. $\mathbf{F}$ change yaitu $\mathbf{0 , 0 0 0}$. $\mathrm{Hal}$ itu berarti nilai Sig. $\mathbf{F}$ change $<\boldsymbol{\alpha}(\mathbf{0}, 05)$, sehingga $\mathrm{HO}_{3}$ ditolak. Oleh karena itu dapat ditarik kesimpulan bahwa terdapat korelasi positif antara gaya dan motivasi 
belajar matematika dengan prestasi belajar matematika. Selain itu, diketahui pula nilai R sebesar 0,501 yang berarti nilai korelasi antara gaya belajar dengan prestasi belajar matematika masuk dalam kategori sedang. Pada hasil analisis tersebut, diketahui pula nilai $\mathbf{R}$ Square yaitu 0,251 yang berarti bahwa variabel gaya dan motivasi belajar matematika secara simultan memberikan sumbangan sebesar $25,1 \%$ pada peningkatan prestasi belajar matematika siswa, sedangkan $74,9 \%$ merupakan sumbangan dari variabel lain. Berasarkan analisis signifikansi, diketahui bahwa nilai $F_{\text {hitung }}$ yaitu 29,934, sedangkan nilai $F_{\text {tabel }}(\mathrm{dk}$ pembilang $=3$ dan dk penyebut $=268$ ) dengan taraf signifikansi $5 \%$ yaitu 3,029. Oleh karena itu, dapat disimpulkan bahwa nilai $\boldsymbol{F}_{\text {hitung }}(\mathbf{2 9}, \mathbf{9 3 4})>\mathbf{F}_{\text {tabel }}(\mathbf{3 , 0 2 9 )}$ yang berarti koefisien korelasi antara gaya dan motivasi belajar matematika dengan prestasi belajar matematika siswa yang ditemukan adalah signifikan (dapat diberlakukan untuk populasi tempat sampel diambil). Hasil analisis hipotesis ketiga dalam penelitian ini sesuai dengan beberapa penelitian yang pernah dilakukan sebelumnya. Penelitian tersebut yaitu penelitian yang dilakukan oleh Ulfa (2016:135). Pada analisis penelitiannya, pada tabel Coeficients diketahui nilai Sig. sebesar 0,000, sehingga Sig. $<\alpha(0,05)$. Hal itu menunjukkan bahwa Ho ditolak dan $\mathrm{H}_{1}$ diterima yang berarti bahwa terdapat pengaruh antara gaya belajar dan motivasi belajar terhadap hasil belajar. Kemudaian pada kolom $\mathrm{R}$ square membuktikan besar pengaruh gaya belajar dan motivasi belajar terhadap hasil belajar sebesar $26 \%$. Selain itu, terdapat juga penelitian yang dilakukan oleh Taiyeb dan Mukhlisa (2015: 16) tentang "Hubungan Gaya Belajar dan Motivasi Belajar dengan Hasil Belajar Biologi Siswa Kelas XI IPA SMA Negeri 1 Tanete Rilau". Penelitian yang dilakukan oleh Taiyeb dan Mukhlisa pada tahun 2015 menghasilkan kesimpulan terdapat hubungan gaya belajar dan motivasi belajar dengan hasil belajar biologi siswa kelas XI IPA SMA Negeri 1 Tanete Rilau.

\section{SIMPULAN}

Berdasarkan hasil penelitian mengenai gaya belajar, motivasi belajar matematika, dan prestasi belajar matematika siswa kelas V SDN se-Kecamatan Klirong tahun ajaran 2017/2018 dapat ditarik kesimpulan sebagai berikut:

1. Gaya belajar berkorelasi positif dengan prestasi belajar matematika siswa kelas $\mathrm{V}$ SDN se-Kecamatan Klirong.

2. Motivasi belajar matematika berkorelasi positif dengan prestasi belajar matematika siswa kelas V SDN se-Kecamatan Klirong.

3. Gaya belajar dan motivasi belajar matematika berkorelasi positif dengan prestasi belajar matematika siswa kelas V SDN se-Kecamatan Klirong.

\section{DAFTAR PUSTAKA}

Bire, A.L., Geradus, U., \& Bire, J. (2014). Gaya Belajar Visual, Auditorial, dan Kinestetik terhadap Prestasi Belajar Siswa. Jurnal Kependidikan, 44 (2), 168174.

Ghufron, M.N. \& Risnawita, R. (2014). Gaya Belajar Kajian Teoristik. Yogyakarta: Pustaka Pelajar.

Gunawan, A.W. (2006). Genius Learning Strategy Petunjuk Praktis untuk Menerapkan Accelarated Learning. Jakarta: PT Ikrar Mandiriabadi.

Jatmiko. (2015). Hubungan Motivasi Belajar dengan Hasil Belajar Matematika Siswa Kelas X SMK Nahdhatul Ulama Pace Nganjuk. Jurnal Math Educator Nusantsara, 1 (2), 205-213.

Mukhid, A. (2007). Meningkatkan Kualitas Pendidikan melalui Sistem Pembelajaran yang Tepat, Tadris, 2 (1) 120 - 133.

Suara Merdeka. (2017, 14 November). Matematika, Penting tetapi tidak Disukai, hlm. 24. 
Sugiyono. (2017). Statistik untuk Penelitian. Bandung: Alfabeta.

Ulfa, F. (2016). Pengaruh Gaya Belajar dan Motivasi Belajar terhadap Hasil Blajar Matematika Siswa Kelas V SDN Dabin I Kecamatan Ulujami Kabupaten Pemalang. Skripsi Tidak Dipublikasikan. Universitas Negeri Semarang, Semarang

Uno, H.B. (2016). Teori Motivasi \& Pengukurannya. Jakarta: Bumi Aksara.

Uno, H.B. \& Kuadrat, M. (2009). Mengelola Kecerdasan dalam Pembelajaran. Jakarta: Bumi Aksara. 